\title{
Analysing discussions around Rural Health on Twitter during the COVID-19 pandemic
}

\author{
Wasim Ahmed ${ }^{1}$, Josep Vidal-Alaball 2,3,4,* and Josep Maria Vilaseca Llobet 4,5 \\ 1 Stirling University Management School, University of Stirling, Stirling, FK9 4LA, Scotland, UK; \\ Wasim.Ahmed@stir.ac.uk \\ 2 Unitat de Suport a la Recerca de la Catalunya Central, Fundació Institut Universitari per a la Recerca a \\ l’Atenció Primària de Salut Jordi Gol i Gurina, 08272 Sant Fruitós de Bages, Spain; jvidal.cc.ics@gencat.cat \\ 3 Health Promotion in Rural Areas Research Group, Gerència Territorial de la Catalunya Central, Institut \\ Català de la Salut, 08272 Sant Fruitós de Bages, Spain \\ 4 Faculty of Medicine, University of Vic - Central University of Catalonia, Vic, ES. josep- \\ maria.vilaseca@umedicina.cat \\ 5 Consorci d'Atenció Primària Barcelona Esquerra. Barcelona. ES \\ * Correspondence: jvidal.cc.ics@gencat.cat ; Tel.: 93693 0040, 08272 Sant Fruitós de Bages
}

\begin{abstract}
Individuals from rural areas are increasingly using social media as a means of communication, receiving information, or actively complaining of inequalities and injustices. This study captured 57 days' worth of Twitter data from June to August 2021 related to rural health using English language keywords. The study utilised social network analysis and natural language processing to analyse the data. It was found that Twitter served as a fruitful platform to raise awareness of problems faced by those living in rural areas. Overall, Twitter was utilised in rural areas to express complaints, to debate, and share information. Twitter could be leveraged as a powerful social listening tool for individuals and organisations who want to gain insight into popular narratives around rural health.
\end{abstract}

Keywords: Rural Health; Twitter Messaging; Social Media; Covid-19; SARS-CoV-2; coronavirus; social network analysis

\section{Introduction}

Globalisation and the proliferation of the World Wide Web and social media has led to an increase in the amount of information available at any time and all over the world. One of the places where getting access to information is crucial is in rural areas. This is because it can help to break traditional isolation to which those living in rural areas may be subjected. In the past, it was believed that rural communities were isolated, with poor access to online information and excluded from social media. This is partially true [1], however in recent times, in both developed and developing countries, a significant number of individuals from rural areas are using social media as a means of communication, to receive updated information and to access quality health support and services [2].

It is well known that several health and societal issues can be found within a rural health setting compared to urban areas. This includes high poverty rates, less access to health care, higher percentage of adults with health problems, and exposure to chemicals from farming.

The use of Twitter as a popular form of social media used for healthcare communication has been studied for several years [3]. Twitter has been used as a means of health promotion by large urban hospitals and clinics in the United States of America [4]. Twitter has also been used as a new source of data to study depression and its wider determinants in deprived populations in India and Brazil and for predictive analytics and sentiment analysis [5]. 
A recent study of scientific literature analysing the implications of Twitter in health-related research identified a high diversity of themes ranging from professional education in healthcare, to big data, social marketing and substance use, physical and emotional well-being of young adults, and public health and health communication [6]. The analysis of social media provides a useful tool for public health specialists and government decision makers to gain insight into population reactions and feelings [7], especially in times of uncertainty like the one we are facing with the present pandemic [8].

A study by Cuomo et al. analysed the geospatial distribution of Tweets related to COVID-19 to try to illustrate the full scope of the pandemic. The authors found that rural areas in the United States of America engaged in COVID-19 social media conversations at later stages compared with urban areas [9].

The place of birth has been regarded as an important determinant of health [10]. The availability of resources in rural areas differs from urban areas and this has an impact on population health [11,12]. Another problem of rural areas is the shortage of health professionals willing to work in these areas [13]. Some initiatives are being developed to promote interest in rural health in this context. One of such initiatives uses social media for this objective. This is the case of the Rural Family Medicine Cafés, which since 2015 has been organising regular meetings using social networks to put in contact health professionals who work or have an interest in rural health $[14,15]$.

There are few studies investigating the use of Twitter in relation to rural health issues and trying to analyse popular topics covered in these areas. This is particularly interesting at the time of the COVID-19 pandemic. The main overall research aim of our study is to analyse the conversations about rural health taking place on Twitter during the COVID-19 pandemic to better understand popular narratives being communicated. Twitter is a popular social networking platform, and our study aims to shed light on the content hosted on the platform related to rural health.

More specifically, the objectives of this study are to:

- Develop an understanding of the content and debates being shared on Twitter.

- To identity influential users around rural health on Twitter.

- To uncover the key hashtags and websites being shared.

\section{Materials and Methods}

\subsection{Sampling Tweets and Ethical Approval}

This study made use of the Twitter Archiving Google Sheets (TAGS) tool to retrieve 15,586 tweets matching the "rural health" keyword. Tweets were retrieved from 10/06/2021 to 06/08/2021 covering 57 days. No particular geographical location was selected, and tweets could be sent and received from anywhere in the world where Twitter in available. This is not a limitation of this study per se as Twitter does not provide accurate location-based data. Although there are numerous definitions for what is rural [16], we have used the principle that if you think you are rural, you probably are.

TAGS draws upon the Twitter Search Application Programming Interface (API) to retrieve tweets. The project received ethical approval from Newcastle University. Although it can be argued that tweets are in the public domain, the project was careful not to draw attention to individual users acting in a personal capacity. However, the users and key tweets reproduced in this study derive either from accounts and users in the public domain, social media influencers, health organisations, politicians, and academic journals.

\subsection{Data Analysis}

The software NodeXL (Social Media Research Foundation, California, CA, USA) was used to conduct a social network analysis of the data [17]. The network graph was laid out using the Clauset-Newman-Moore layout algorithm that is integrated into NodeXL. Natural language processing (NLP) was applied to the tweets in order to identify 
word-pair correlations on the clusters identified from the social network analysis. NodeXL was used to run the NLP which helped to identify correlated word-pairs in each of the clusters.

In order to identify influential users the metric of betweenness centrality was applied which is derived from network theory and is used in this paper as a way of finding Twitter users that have influence in our dataset. This methodology has been used by the authors in previous research [19-20]. This metric was used in this study as it can identify users located in strategic locations within the network and who are gatekeepers of information propagation.

Providing a detailed overview of network visualisations is beyond the scope of this study. Those new to network visualisations may wish to examine research in this area, which outlines common network patterns and how to interpret them [21].

\section{Results}

\subsection{Results of Social Network Analysis}

Figure 1 provides a visual representation of the Twitter activity based on the data that was captured. Circles represent individual Twitter users that were tweeting using the words 'rural health' and the lines between them represent connections such as mentions and replies. Different colours are used to distinguish each of the groups, and they are listed from left to right ranked by size where group 1 is the largest cluster in the network followed by group 2 and so forth.

The figure highlights how there were a number of different groups of users that were conversing about different topics related to rural health. The largest group in the network (group 1) is that of a broadcast network where a small number of users are retweeted with high frequency.

There are also a number of other smaller groups and broadcast networks giving the overall network a community shape. Other popular groups such as group 3, 5, 6, 7, and 10 indicate that there were different communities forming on Twitter which were conversing about different topics. Group 9 appears to be a broadcast network shape. Appendix 1 contains a full list of keywords associated with each of the clusters, which provide insight into the types of topics that were being discussed.

Aside from 'rural, health' itself, the most popular co-word combination in group 1 was that of 'fighting, covid' ( $\mathrm{n}=873$ ). Other interesting keywords identified within this group included, 'busting, myths' $(\mathrm{n}=873)$ indicating the combatting of misinformation. The tweet ranked number 3 in regard to attracting the most retweets (in Table 4) may account for some of these keywords. In group 2, interesting word-combinations included 'health, systems' ( $\mathrm{n}=373)$, 'expanding, medicaid' $(\mathrm{n}=256)$, 'taxpayers, money' $(\mathrm{n}=254)$, and 'affordable, health' $(\mathrm{n}=212)$. 


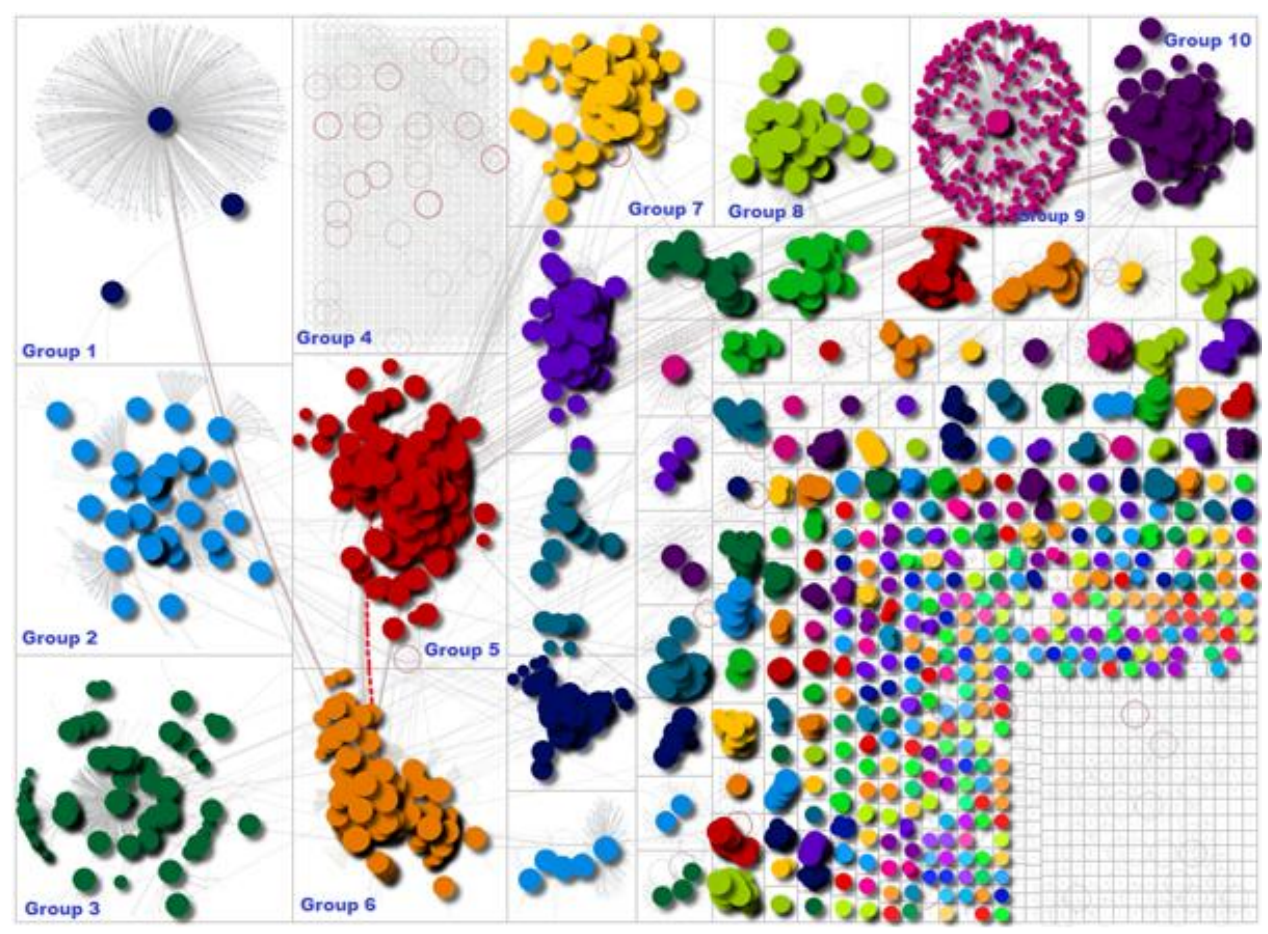

Figure 1. Social network visualization and discussions across groups.

\subsection{Results of Time Series Analysis}

Figure 2 provides an overview of the unique edges (i.e., tweets, retweets, mentions etc.) within the dataset. There appears to be a constant stream of Twitter activity with two large peaks taking place on the 18th of June and the 16 of July, respectively. Overall, there appears to be much more activity taking place during June 2021. These peaks relate to spikes in retweets due to the tweets contained in Table 4.

\section{Count of unique edges by day}

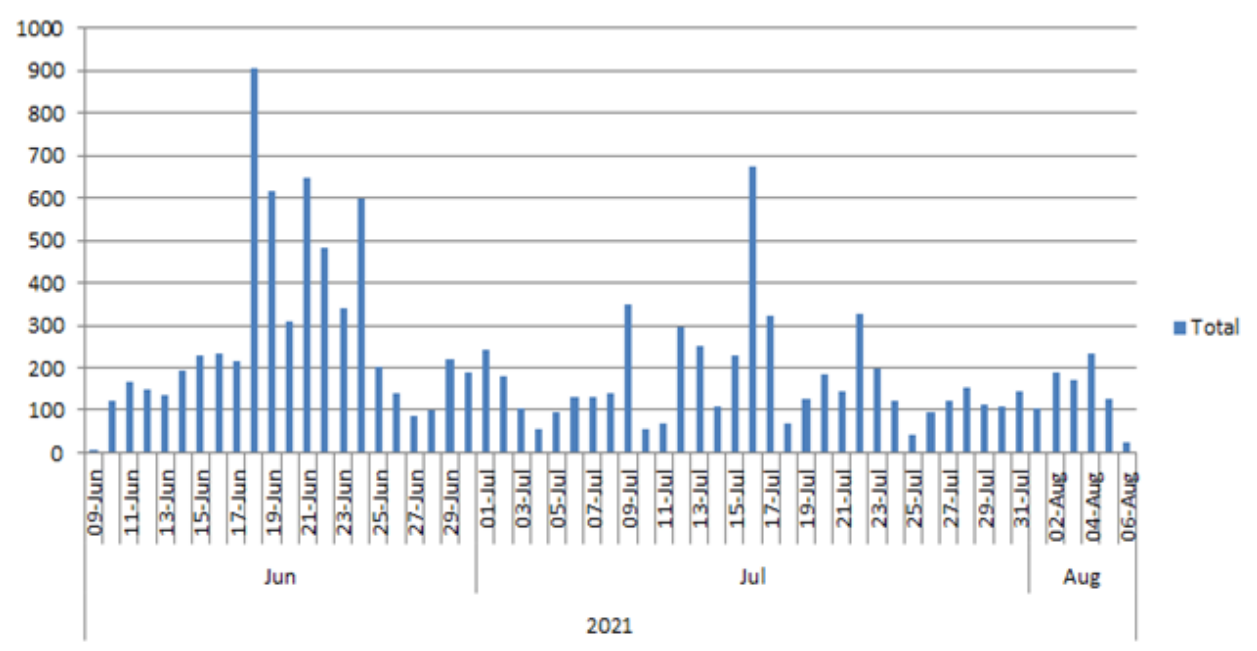

Figure 2. Time series chart of Twitter activity.

\subsection{Results Related to key users, websites, hashtags, and retweets}

Table 1 provides insight into the key users. The first key user is the account of Akhilesh Yadav, Socialist Leader of India. This is followed by the Twitter account of the 
World Health Organization (WHO) and the Rural and Remote Health Journal Twitter, an open-access academic international journal. In fourth place we found the account of Senator Reverend Raphael Warnock, United States Senator from Georgia and in fifth the account of the National Rural Health Association, a US non-profit organization with the mission to provide leadership on rural health issues through advocacy, communications, education, and research.

Table 1. Key Users by Betweenness Centrality.

\begin{tabular}{lll}
\hline User handle & Bio & $\begin{array}{l}\text { Betweenness } \\
\text { Centrality }\end{array}$ \\
\hline yadavakhilesh & Socialist Leader of India. Chief Minister of & 5185471 \\
& UP $(2012-2017)$ & \\
\end{tabular}

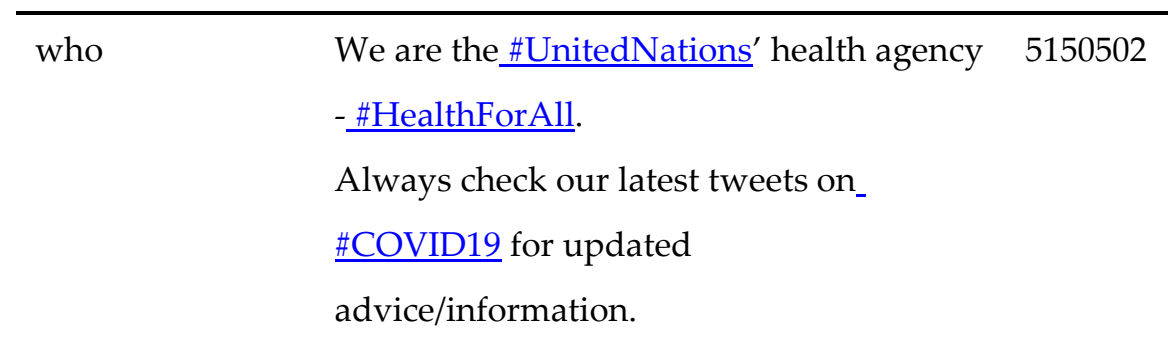

\begin{tabular}{ll}
\hline rrh_journal & Open-access, peer-reviewed journal \\
& providing an international evidence base \\
& to inform improvement in rural and \\
& remote health (free-to-read, no page \\
& charges)
\end{tabular}

senatorwarnock $\quad$ United States Senator from Georgia. 3855435

Pastor of Ebenezer Baptist Church.

\begin{tabular}{lll}
\hline ruralhealth & National Rural Health Association, 21k+ 3000683 \\
& members nationwide, providing \\
& leadership and support at NRHA. \\
\hline bprophetable & Only way to get good politicians is get rid 2476886 \\
& of bad ones. I try to retweet facts and \\
& everyone's opinions including those I \\
& disagree with \#FactsMatter \\
& \\
\hline dainikbhaskar & India's Biggest Hindi Newspaper \& News 2403907 \\
& App. For Realtime News Updates, Local \\
\hline
\end{tabular}


News for 2000 cities, Short Video News,

Download our App:-

http://dainik-b.in/riOAhsOKg6

\begin{tabular}{lll}
\hline nytopinion & We amplify voices on the issues that & 2372269 \\
& matter to you. I Tell us what you think: \\
& letters@nytimes.com \\
\hline timryan & Proud dad and husband, Ohio native, \\
& die-hard Browns fan. Running for U.S. \\
& Senate to fight like hell to cut workers in \\
& on the deal. \\
& \\
& Rural Doctors Association of Australia - 2209906 \\
& promoting excellent medical care for rural \\
ruraldoctorsaus & and remote Australians.
\end{tabular}

Table 2 provides information about the top websites used in tweets. The top website used in tweets and by far ( 877 occurrence) is one from The Verge, an American technology news website. It features an article on how health care workers are fighting misinformation about COVID-19 in rural India. The second most used website in tweets, but with significantly less graph count is one related to India as well. It is an article from The New York Times talking about how the bodies floating at the river Ganges and buried at their shores showed that the authorities were not telling the truth about the full extent of the death toll caused by COVID-19. The third most used website was from a suspended account. Finally, the fourth most used website was from Gary Votour, running for Governor of South Carolina (US) and the fifth was an article from IndiaSpend, an Indian on-line journal, talking about how Indian rural health centres were struggling with staff shortages, especially pharmacists and doctors.

Table 2. Top websites used in tweets.

\begin{tabular}{llc}
\hline Rank & Title & Count \\
\hline 1 & $\begin{array}{l}\text { India's Healthcare Workers Are Busting Misinformation } \\
\text { On WhatsApp }\end{array}$ & 877 \\
\hline 2 & The Ganges Is Returning the Dead. It Does Not Lie. & 164 \\
\hline 3 & This tweet is from a suspended account & 115 \\
\hline 4 & Official campaign website for Gary Votour for Governor of & 89 \\
\hline
\end{tabular}




\section{As Third Wave Looms, Rural Health Centres Struggle 69}

With Expired Drugs, Missing Doctors

\begin{tabular}{|c|c|c|}
\hline 6 & $\begin{array}{l}\text { Myth Vs Facts Government of India has been working } \\
\text { towards effective COVID-19 management in rural India by } \\
\text { sustained strengthening of the Rural health Infrastructure, } \\
\text { and through focussed Public Health Measures in active } \\
\text { collaboration with the States }\end{array}$ & 61 \\
\hline 7 & Gary Votour for South Carolina Governor campaign & 60 \\
\hline 8 & $\begin{array}{l}\text { Chhattisgarh to privatise rural health infra; public health } \\
\text { experts and activists demand roll back }\end{array}$ & 55 \\
\hline 9 & $\begin{array}{l}\text { Official Account Of Chhattisgarh Pradesh Congress } \\
\text { Committee. }\end{array}$ & 47 \\
\hline 10 & $\begin{array}{l}\text { Barak Obama's twitter account, it reads: Today, the } \\
\text { Supreme Court upheld the Affordable Care Act. Again. } \\
\text { This ruling reaffirms what we have long known to be true: } \\
\text { the Affordable Care Act is here to stay. }\end{array}$ & 47 \\
\hline
\end{tabular}

Table 3 provides insight into the top hashtags used in tweets. The most used hashtag is \#appoint_pharmacist_for_rural_health a hashtag used in a campaign to advocate for the appointment of pharmacists in rural India. The second most used hashtag was \#33yearsofpmk a hashtag commemorating 33 years of the Paattali Makkal Katchi (Working people's party) abbreviated as PMK, a political party in Tamil Nadu, India. The third hashtag is directly related to rural health: \#ruralhealth and the fourth and fifth are to hashtags, one in English and the other in Korean to celebrate the birthday of Sunoo (Birth Name: Kim Sun-oo), member of the Korean band ENHYPEN. The hashtags related to COVID-19 come in 6th and 10th position.

Table 3. Top hashtags used in tweets.

\begin{tabular}{ll} 
Top Hashtags & Occurrence \\
\hline appoint_pharmacist_for_rural_health & 1498 \\
\hline 33yearsofpmk & 573 \\
\hline ruralhealth & 353 \\
\hline sunooourmiracleofjune & 341 \\
\hline 눈부신_선우의_열아홉번째_생일 & 339
\end{tabular}




\begin{tabular}{lc} 
covid19 & 302 \\
\hline pharmacistfederation & 287 \\
\hline rural & 198 \\
\hline medicaidsaveslivesact & 157 \\
\hline covid & 147
\end{tabular}

Table 4 provides information about the top ten retweets identified in the dataset. The first, second and fourth retweets are addressed to specific individuals. The first one is an appeal to the Prime Minister of India to appoint more rural doctors and the second and fourth ones are in relation to a campaign to uncover water corruption in rural areas. The third is a recognition of rural health activists and they work fighting misinformation about COVID-19 in rural India. The others have several purposes related to rural and public health: to report corruption related to rural health problems and the deplorable conditions of rural health care facilities, to congratulate a doctor by giving some key indicators of a Rural Health program milestone, to announce the building of healthcare facilities and to report the shortage of health workforce and encourage professionals to work in rural areas.

Table 4. Top Ten Retweets.

\begin{tabular}{|c|c|c|}
\hline Rank & Tweet Content & Occurrence \\
\hline 1 & 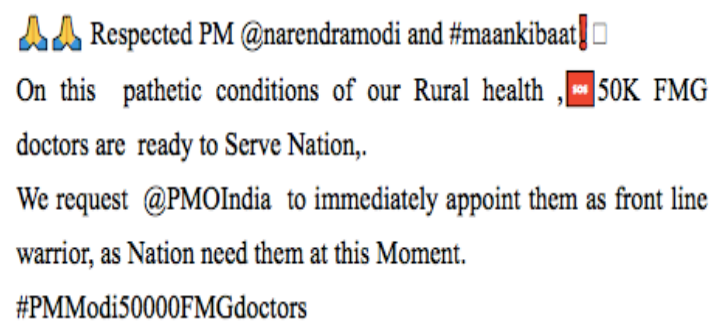 & 1079 \\
\hline 2 & $\begin{array}{l}\text { I've been criticised for talking to "crude } \\
\text { comedian" @friendlyjordies } \\
\text { But in my } 18 \text { mths as Member for Murray, not } \\
\text { one Sydney journo has come here. FJ spent } \\
\text { two days here uncovering water corruption } \\
\text { \& rural health crisis, do I ignore him b/c he } \\
\text { uses cuss words? \#nswpol \#auspol }\end{array}$ & 1025 \\
\hline 3 & $\begin{array}{l}\text { Fighting Covid isn't just a question about } \\
\text { health, it's also about busting myths in our } \\
\text { social media world. I want to thank all our } \\
\text { front line rural health activists who are } \\
\text { combatting COVID with facts and science! } \\
\text { https://t.co/s7rlY2FNal }\end{array}$ & 899 \\
\hline
\end{tabular}


4 Both @friendlyjordies and Alan Jones have 558

interviewed me several times: on water

corruption and the rural health crisis. I'm

constantly asked to justify/defend unrelated

things FJ have said/done in the past. But I

never get the same questions about Alan

Jones.

Why is that?

5 Rural health care facilities in shambles in 414

\#UttarPradesh! Here's a detailed report.

\#ITVideo \#CoronavirusCrisis

https://t.co/RZRvoPjaeT

6 "What's your degree? "Public Health" 407

"Ay ang sad, you work in communities? Mas

maganda sa hospital"

SO WHAT'S WRONG WITH WORKING IN

COMMUNITIES? IN RURAL HEALTH

UNITS? IN GIDA? WE NEED MORE

HEALTH WORKERS THAT WILL SERVE

IN RURAL AREAS https://t.co/wtzbjbIJap

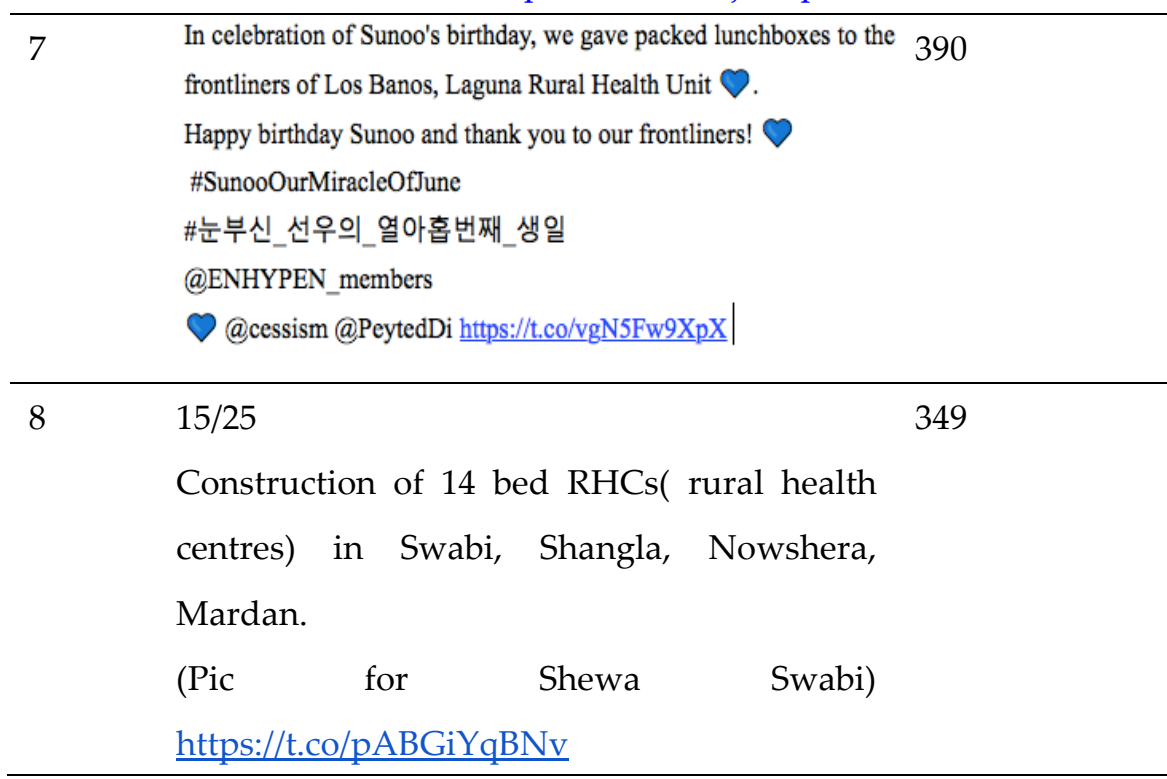




\title{
। इनके भवन निर्माण खर्च व उक्त केंद्रों में तैनात
}

कर्मियों को दिया जाने वाला हज़ारों करोड़ कहां

\section{जा रहा है? नीतीश सरकार इन जर्जर केंद्रों को
https:/tt.co/dOtEdiUtep4}

\section{कागजी तौर पर चलाकर सुनियोजित तरीके से सं Google translate: More than 1000 health

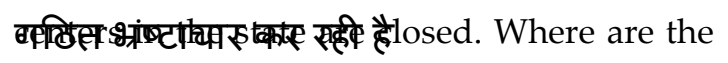
thousands of crores given to their building construction expenses and the personnel posted in the said centers going? Nitish government is doing organized corruption in a systematic manner by running these dilapidated centers on paper.

\begin{tabular}{l}
\hline 10 Dr. Anbumani has established the National \\
Rural Health Mission (NRHM) in 2005, 10 \\
years post implementation of the NRHM \\
India's MMR today 166/1L deliveries
\end{tabular}

IMR is reduced to $41 / 1 \mathrm{~K}$ live births.

An evergreen milestone of Indian health ministry

\#PMKinIndianGovernance

\begin{abstract}
If we consider the retweet count shown in table 4, it is clear the most widely used language is English, either in non-English native speaking areas or in countries where other local languages are spoken. In total, 4,553 retweets (80\%) are written only in English. If we include tweets that are mixing English and other languages, it accounts for 94.5 $\%$ (5,350 retweets). It seems that English is used as a lingua franca to reach a wider audience on Twitter. The second most used language is Tagalog, mixed with English in the main body of the Tweet ( 407 retweets, $7 \%$ ). The third most used language is Korean, but in this case used only as a hashtag, being the main text of the tweet in English (390 retweets, $6.9 \%$ ). The fourth one is Hindi, being only used in one out of the top ten retweets in our dataset (311 retweets, $5.5 \%$ ).
\end{abstract}

\subsection{Results Related to Geographical Locations}

The geographical location of the debates is mainly in India, Pakistan, Australia, Philippines, and the United States of America. The most widely used language is English. Other languages used are Hindi, Korean and Tagalog.

\section{Discussion}


Although the role of social media in rural settings has been studied previously [2, 15], as far as we are aware, this is the first study on the specific use of Twitter in relation to rural health issues and analyses the common topics discussed in these settings.

Regarding language, our study identified that the Latin alphabet was the most widely used. The study also found that Devanagari was also used for the text body of the tweet, and the Korean alphabet was used on occasion only for the hashtag part oof tweets (the main body of the tweet is written in English). The Tagalog language was written in the Latin alphabet. Although Chinese is one of the largest populations in the world our study didn't observe use of the Chinese language on this topic. This can be explained by the restrictions placed on accessing Twitter in China. Although a longer follow-up may change the distribution of most widely used languages and alphabets, it seems that the English and Latin alphabets are overwhelmingly used on Twitter related to this topic.

Our study found that the key users related to this topic are not only individuals (mainly politicians), but also organisations dealing with aspects related to rural health. The top websites used in the tweets are neither specialised in healthcare nor in public health. The tweets sometimes use wide audience sources, like international newspapers (The New York Times) or local press.

It was found that some of the top hashtags were not strictly related to rural health. They included a celebration of the anniversary of a member of a top Korean boy band and the anniversary of the foundation of an Indian political party, although this political party has strong relations with rural areas. The most used hashtag relates to a campaign claiming for the appointment of a pharmacist in rural areas, indicating the shortage of pharmacists in these settings. The COVID-19 hashtag is also popular, being used in two different forms (covid19 and covid). However, during the time-period examined, this is not the top hashtag, probably due to a shift to other health concerns and the decrease in the number of cases worldwide during the period monitored.

The top ten retweets explicitly mention rural health, healthcare, or public health problems. The topics are in general of local interest, pointing at very specific issues. Even when rural health is part of a politician campaign or a politician's comment, its interest is local or national. The main uses of Twitter identified in our study are complaints, debates, information sharing, acknowledgements, advertisements, and politician's campaigns.

Regarding the geographical location of the top tweets, the location with the most influential tweets derived from India. This is not surprising given the size of India and the number of rural areas. The United States, the Philippines, and South Korea are also amongst the most frequent locations where influential tweets were being sent from.

The study has several limitations. A circumscribed 57-day time period was examined which may have excluded certain tweets falling outside this period. Another limitation is that the Search API used can only retrieve data from public facing Twitter accounts and not from private accounts, however, the majority of accounts are set as public. Another limitation is that as our study retrieved data using a very specific keyword (rural health), our data may have excluded tweets from users who tweeted without using our target keyword. Furthermore, the study did not pick up many tweets from other widely spoken languages such as German or French that may arise from the limited number of keywords used when retrieving data. Future research could seek to build a more comprehensive dataset by drawing up other languages. For all this reasons, the results of this study cannot be generalised,

Assessing needs for those living in rural communities has traditionally been challenging. Several circumstances have been a constraint: language as a barrier, isolation, lack of registries, difficulties to carry out interviews, location of the households, and expenditure to perform studies. Twitter could prove to be a solution for these problems and could be used as a social listening tool to identify the concerns and needs of rural communities. Our study shows that Twitter can be effectively used at least in a couple of ways: as a means of communication in rural areas and as a source of information on rural health. Moreover, the information existing on Twitter, when filtered by geographical lo- 
cations, may be of interest for stakeholders, healthcare workers, politicians, patients, and communities in general.

Twitter could also be used strategically for those living in rural areas to communicate with one-another, for sharing local updates and warning of disasters such as areas to avoid. It could also be used as a way of connecting for sharing resources and supplies. This could be facilitated through the use of domain-specific hashtags related to each area and widely advertised and popularized locally.

\section{Conclusions}

Twitter has been shown to be a powerful means of communication to converse about important issues around rural health. Twitter is a tool that can be used to raise awareness of the problems existing in rural health. When examining tweets in English, it was found that India is the country with the most Twitter related conversations on rural health. Twitter was used to discuss rural settings, and in particular to express complaints, to debate, to share information, to acknowledge somebody or something, and to create advertisements or politician's campaigns. Twitter could be leveraged as a powerful source of information for individuals and organisations working on rural health, and as a means to identify popular narratives and hot issues around this topic.

Supplementary Materials: The following are available online at www.mdpi.com/xxx/s1, Figure S1: title, Table S1: title, Video S1: title.

Author Contributions: For research articles with several authors, a short paragraph specifying their individual contributions must be provided. The following statements should be used "Conceptualization, X.X. and Y.Y.; methodology, X.X.; software, X.X.; validation, X.X., Y.Y. and Z.Z.; formal analysis, X.X.; investigation, X.X.; resources, X.X.; data curation, X.X.; writing-original draft preparation, X.X.; writing-review and editing, X.X.; visualization, X.X.; supervision, X.X.; project administration, X.X.; funding acquisition, Y.Y. All authors have read and agreed to the published version of the manuscript." Please turn to the CRediT taxonomy for the term explanation. Authorship must be limited to those who have contributed substantially to the work reported.

Funding: Please add: "This research received no external funding" or "This research was funded by NAME OF FUNDER, grant number XXX" and "The APC was funded by XXX". Check carefully that the details given are accurate and use the standard spelling of funding agency names at https://search.crossref.org/funding. Any errors may affect your future funding.

Institutional Review Board Statement: In this section, please add the Institutional Review Board Statement and approval number for studies involving humans or animals. Please note that the Editorial Office might ask you for further information. Please add "The study was conducted according to the guidelines of the Declaration of Helsinki, and approved by the Institutional Review Board (or Ethics Committee) of NAME OF INSTITUTE (protocol code XXX and date of approval)." OR "Ethical review and approval were waived for this study, due to REASON (please provide a detailed justification)." OR "Not applicable." for studies not involving humans or animals. You might also choose to exclude this statement if the study did not involve humans or animals.

Informed Consent Statement: Any research article describing a study involving humans should contain this statement. Please add "Informed consent was obtained from all subjects involved in the study." OR "Patient consent was waived due to REASON (please provide a detailed justification)." OR "Not applicable." for studies not involving humans. You might also choose to exclude this statement if the study did not involve humans.

Written informed consent for publication must be obtained from participating patients who can be identified (including by the patients themselves). Please state "Written informed consent has been obtained from the patient(s) to publish this paper" if applicable.

Data Availability Statement: In this section, please provide details regarding where data supporting reported results can be found, including links to publicly archived datasets analyzed or generated during the study. Please refer to suggested Data Availability Statements in section "MDPI Research Data Policies" at https://www.mdpi.com/ethics. You might choose to exclude this statement if the study did not report any data. 
Acknowledgments: In this section, you can acknowledge any support given which is not covered by the author contribution or funding sections. This may include administrative and technical support, or donations in kind (e.g., materials used for experiments).

Conflicts of Interest: Declare conflicts of interest or state "The authors declare no conflict of interest." Authors must identify and declare any personal circumstances or interest that may be perceived as inappropriately influencing the representation or interpretation of reported research results. Any role of the funders in the design of the study; in the collection, analyses or interpretation of data; in the writing of the manuscript, or in the decision to publish the results must be declared in this section. If there is no role, please state "The funders had no role in the design of the study; in the collection, analyses, or interpretation of data; in the writing of the manuscript, or in the decision to publish the results".

\section{Appendix 1}

Table 5. Word-Pairs Associated with Groups.

\begin{tabular}{cc}
\hline Top Word Pairs in Tweet in G1 & G1 Count \\
\hline rural,health & 874 \\
\hline fighting,covid & 873 \\
\hline covid,question & 873 \\
\hline question,health & 873 \\
\hline health,busting & 873 \\
\hline busting, myths & 873 \\
\hline myths, social & 873 \\
\hline social,media & 873 \\
\hline media, world & 873 \\
\hline world,line & 873 \\
\hline
\end{tabular}

Table 6. Word-Pairs Associated with Groups.

\begin{tabular}{cc}
\hline Top Word Pairs in Tweet in G2 & G2 Count \\
\hline rural,health & 834 \\
\hline health,care & 732 \\
\hline health,systems & 373 \\
\hline expanding,medicaid & 256 \\
\hline taxpayers,money & 254 \\
\hline care,georgia & 216 \\
\hline improve,health & 216 \\
\hline health,outcomes & 216 \\
\hline access,affordable & 212 \\
\hline affordable,health & 212 \\
\hline
\end{tabular}

Table 7. Word-Pairs Associated with Groups.

\begin{tabular}{cc}
\hline Top Word Pairs in Tweet in G3 & G3 Count \\
\hline alan,jones & 1058 \\
\hline rural,health & 684 \\
\hline health,crisis & 618 \\
\hline water,corruption & 560 \\
\hline corruption,rural & 560 \\
\hline friendlyjordies,alan & 529 \\
\hline jones,interviewed & 529 \\
\hline interviewed,times & 529 \\
\hline times, water & 529 \\
\hline
\end{tabular}


crisis,constantly

Table 8. Word-Pairs Associated with Groups.

\section{Top Word Pairs in Tweet in G4}

rural,health

health,care

G4 Count

health,clinics

748

\begin{tabular}{cc} 
rural,health & 748 \\
\hline health,care & 131 \\
\hline health,clinics & 89 \\
\hline covid,19 & 80 \\
\hline health,unit & 67 \\
\hline health,clinic & 29 \\
\hline role,rural & 27 \\
\hline increasing,advanced & 25 \\
\hline advanced,practice & 25 \\
\hline practice,providers & 25 \\
\hline
\end{tabular}

Table 9. Word-Pairs Associated with Groups.

Top Word Pairs in Tweet in G5

rural,health

G5 Count

health,care

871

sam,rural

117

health, advocate

101

health,clinics

100

health,conference

97

rural,communities

72

national,rural

53

rural,america

52

covid,19

51

46

Table 10. Word-Pairs Associated with Groups.

\begin{tabular}{cc}
\hline Top Word Pairs in Tweet in G6 & G6 Count \\
\hline य,क & 4176 \\
\hline र,म & 3793 \\
\hline क,न & 2784 \\
\hline न,य & 2784 \\
\hline क,त & 2784 \\
\hline फ,र & 2401 \\
\hline म,स & 2401 \\
\hline स,स & 2401 \\
\hline स,ट & 2401 \\
\hline ट,क & 2401 \\
\hline
\end{tabular}

Table 11. Word-Pairs Associated with Groups.

\begin{tabular}{cc}
\hline Top Word Pairs in Tweet in G7 & G7 Count \\
\hline rural,health & 226 \\
\hline health,centres & 110 \\
\hline primary,health & 69 \\
\hline health,infrastructure & 68 \\
\hline
\end{tabular}




\begin{tabular}{cc}
\hline healthcare,system & 58 \\
\hline private,hospitals & 52 \\
\hline state,level & 52 \\
\hline level,organisations & 52 \\
\hline organisations,protest & 52 \\
\hline infrastructure,rural & 52 \\
\hline
\end{tabular}

Table 12. Word-Pairs Associated with Groups.

\begin{tabular}{cc}
\hline Top Word Pairs in Tweet in G8 & G8 Count \\
\hline rural,health & 431 \\
\hline health,care & 425 \\
\hline destroying,rural & 243 \\
\hline attacking,family & 214 \\
\hline family,physicians & 214 \\
\hline physicians,destroying & 214 \\
\hline health,networks & 214 \\
\hline networks,alienating & 214 \\
\hline alienating,nurses & 214 \\
\hline nurses,dismantling & 214 \\
\hline
\end{tabular}

Table 13. Word-Pairs Associated with Groups.

\begin{tabular}{cc}
\hline Top Word Pairs in Tweet in G9 & G9 Count \\
\hline rural,health & 341 \\
\hline happy,birthday & 341 \\
\hline birthday,sunoo & 341 \\
\hline celebration,sunoo's & 339 \\
\hline sunoo's,birthday & 339 \\
\hline birthday, packed & 339 \\
\hline packed,lunchboxes & 339 \\
\hline lunchboxes,frontliners & 339 \\
\hline frontliners,los & 339 \\
\hline los,banos & 339
\end{tabular}

Table 14. Word-Pairs Associated with Groups.

\begin{tabular}{cc}
\hline Top Word Pairs in Tweet in G10 & G10 Count \\
\hline rural,health & 413 \\
\hline health,care & 65 \\
\hline health,commissioner & 61 \\
\hline health,workforce & 32 \\
\hline national,rural & 32 \\
\hline ruth,stewart & 30 \\
\hline rural,remote & 29 \\
\hline health,brink & 26 \\
\hline brink,workforce & 26 \\
\hline workforce,cliff & 26 \\
\hline
\end{tabular}

\section{References}


1. Greenberg AJ, Haney D, Blake KD, Moser RP, Hesse BW. Differences in Access to and Use of Electronic Personal Health Information Between Rural and Urban Residents in the United States. J Rural Heal. 2018;34:s30-8.

2. Mehmet M, Roberts R, Nayeem T. Using digital and social media for health promotion: A social marketing approach for addressing co-morbid physical and mental health. Aust J Rural Health. 2020;28(2):149-58.

3. Pershad Y, Hangge PT, Albadawi H, Oklu R. Social Medicine: Twitter in Healthcare. J Clin Med. 2018 May 28;7(6):121. doi: 10.3390/jcm7060121. PMID: 29843360; PMCID: PMC6025547.

4. Kordzadeh N. Health promotion via Twitter: a case study of three medical centers in the USA. Health Promot Int. 2021 Aug 11:daab126. doi: 10.1093/heapro/daab126. Epub ahead of print. PMID: 34379755.

5. Thapa B, Torres I, Koya SF, Robbins G, Abdalla SM, Arah OA, Weeks WB, Zhang L, Asma S, Morales JV, Galea S, Rhee K, Larson HJ. Use of Data to Understand the Social Determinants of Depression in Two Middle-Income Countries: the 3-D Commission. J Urban Health. 2021 Aug 18:1-10. doi: 10.1007/s11524-021-00559-6. Epub ahead of print. PMID: 34409557; PMCID: PMC8373292.

6. Yeung AWK, Kletecka-Pulker M, Eibensteiner F, Plunger P, Völkl-Kernstock S, Willschke H, Atanasov AG. Implications of Twitter in Health-Related Research: A Landscape Analysis of the Scientific Literature. Front Public Health. 2021 Jul 9;9:654481. doi: 10.3389/fpubh.2021.654481. PMID: 34307273; PMCID: PMC8299201.

7. Vidal-Alaball J, Fernandez-Luque L, Marin-Gomez F, Ahmed W. A New Tool for Public Health Opinion to Give Insight Into Telemedicine: Twitter Poll Analysis. JMIR Form Res 2019;3(2):e13870. URL: https://formative.jmir.org/2019/2/e13870 DOI: $10.2196 / 13870$

8. De Rosis S, Lopreite M, Puliga M, Vainieri M. The early weeks of the Italian Covid-19 outbreak: sentiment insights from a Twitter analysis. Health Policy. 2021 Aug;125(8):987-994. doi: 10.1016/j.healthpol.2021.06.006. Epub 2021 Jun 18. PMID: 34176671; PMCID: PMC8226063.

9. Cuomo RE, Purushothaman V, Li J, Cai M, Mackey TK. Sub-national longitudinal and geospatial analysis of COVID-19 tweets. PLoS One. 2020;15(10 October):1-11. doi:10.1371/journal.pone.0241330

10. Cofiño Fernández R. Tú código postal es más importante para tu salud que tu código genético (1) [Your post code is more important for your health than your genetic code (1)]. Aten Primaria. 2013 Mar;45(3):127-8. Spanish. doi: 10.1016/j.aprim.2013.02.001. PMID: 23499154; PMCID: PMC6985478.

11. Lee H, Lin CC, Snyder JE. Rural-Urban Differences in Health Care Access Among Women of Reproductive Age: A 10-Year Pooled Analysis. Ann Intern Med. 2020 Dec 1;173(11 Suppl):S55-S58. doi: 10.7326/M19-3250. PMID: 33253026.

12. Rahman M, White EM, Thomas KS, Jutkowitz E. Assessment of Rural-Urban Differences in Health Care Use and Survival Among Medicare Beneficiaries With Alzheimer Disease and Related Dementia. JAMA Netw Open.2020;3(10):e2022111. doi:10.1001/jamanetworkopen.2020.22111

13. Lehmann, U., Dieleman, M. \& Martineau, T. Staffing remote rural areas in middle- and low-income countries: A literature review of attraction and retention. BMC Health Serv Res 8, 19 (2008). https://doi.org/10.1186/1472-6963-8-19

14. Floss M. How to Do a Rural Cafe: A Short Manual. 1st ed. (2018). [E-book]. Available online at: https://wonca.net/site/DefaultSite/filesystem/documents/Groups/Rural\%20Practice/Manual\%20Rural\%20Cafe.pdf (accessed August 14, 2021). 
15. Wheatley A, Floss M, Bakola M, Kampouraki M, Silveira B, Scott-Jones J. The Rural Family Medicine Café Project: A Social Media Strategy to Reduce Occupational Isolation and Improve Support for Rural Healthcare Professionals. Front Public Health. 2020 Nov 19;8:595255. doi: 10.3389/fpubh.2020.595255. PMID: 33330339

16. Hart LG, Larson EH, Lishner DM. Rural definitions for health policy and research. Am J Public Health. 2005;95(7):1149-1155. doi:10.2105/AJPH.2004.042432

17. Ahmed, W.; Lugovic, S. Social media analytics: Analysis and visualisation of news diffusion using NodeXL. Online Inf. Rev. 2019, 43, 149-160.

18. Ahmed, W.; Marin-Gomez, X.; Vidal-Alaball, J. Contextualising the 2019 E-Cigarette Health Scare: Insights from Twitter. Int. J. Environ. Res. Public Health 2020, 17, 2236.

19. Ahmed, W.; Vidal-Alaball, J.; Downing, J.; Seguí, F.L. COVID-19 and the 5G Conspiracy Theory: Social Network Analysis of Twitter Data. J. Med. Internet Res. 2020, 22, e19458.

20. Ahmed, W.; Vidal-Alaball, J.; Lopez Segui, F.; Moreno-Sánchez, P.A. A Social Network Analysis of Tweets Related to Masks during the COVID-19 Pandemic. Int. J. Environ. Res. Public Health 2020, 17, 8235. https://doi.org/10.3390/ijerph17218235

21. Smith, M. A., Himelboim, I., Rainie, L., \& Shneiderman, B. (2015). The structures of Twitter crowds and conversations. In Transparency in social media (pp. 67-108). Springer, Cham. 